\title{
ASPECTOS SANITÁRIOS E PRODUTIVOS DAS UNIDADES DE TERMINAÇÃO SUINICOLAS DO ESTADO DE MATO GROSSO, BRASIL
}

\author{
M.B.V. Corrêa ${ }^{1,2 *}$, D.M. Aguiar ${ }^{1}$, J.G. Caramori Júnior ${ }^{3}$ \\ ${ }^{1}$ Universidade Federal de Mato Grosso, Faculdade de Agronomia, Medicina Veterinária e Zootecnia, De- \\ partamento de Clínica Médica Veterinária, Av. Fernando Corrêa, 2367, CEP 78060-900, Cuiabá, MT, Brasil. \\ E-mail: maristelabvc@hotmail.com.
}

\section{RESUMO}

\begin{abstract}
O presente trabalho analisou os aspectos sanitários e produtivos das Unidades de Terminação (UT) suinícolas do Estado de Mato Grosso. Foram levantados dados oficiais junto ao Instituto de Defesa Agropecuária do Estado de Mato Grosso, referentes a 55 granjas de terminação, distribuídas em 18 municípios, no período de dezembro de 2005 a janeiro de 2006. As características foram descritas e analisadas pelo teste de correlação Spearman, segundo o número de animais por UT, aspectos produtivos, sistemas de proteção sanitária, controle de possíveis veiculadores de agentes patogênicos e manejo dos animais. A população suína cadastrada totalizou 74.650 animais, sendo que $44(80,0 \%)$ UT encontravam-se na região do cerrado. Segundo o número de suínos 10,9\%, $9,1 \%, 14, \%, 18,2 \%, 21,8 \%$ e $25 \%$ possuíam de 1 a 10, 11 a 100, 101 a 500, 501 a $1.000,1.001$ a 2.000 e acima de 2.000 suínos, respectivamente. As granjas integradas totalizaram $63,6 \%$ sendo que $89,1 \%$ empregavam manejo intensivo. As analises de correlações positivas $(\mathrm{P}<0,05)$ foram observadas em diversos tipos de granjas, apresentando relação com: assistência veterinária, sistemas all-in allout, incineração de carcaças, vassoura de fogo, compostagem, edificações de alvenaria e madeira, consumo de ração própria e comercial, abastecimento de água de represa, rio ou córregos e controle de moscas. Mesmo observando diferentes índices de correlação, detectaram-se inúmeros déficits de manejo sanitário em diversos segmentos das UT, por isso, questões relativas à biosseguridade das granjas do Estado de Mato Grosso devem ser revistas para que, futuramente, possa ser avaliado o grau de vulnerabilidade delas.
\end{abstract}

PALAVRAS-CHAVE: Granjas, sanidade, suinocultura, Mato Grosso.

\section{ABSTRAT}

SANITARY ANDPRODUCTION ASPECTSOFSWINE FINISHINGUNITSOF MATOGROSSO STATE, BRAZIL. The present study examined health and productive aspects of swine Finishing Units (FU) in Mato Grosso State, Brazil. Data were collected by the official Institute of Agricultural Protection of Mato Grosso State, considering 55 finishing farms, distributed in 18 municipalities in the period from December 2005 to January 2006. The data were described and analyzed by the Spearman correlation test, according to the number of animals per FU, productive aspects, health protection systems, control of potential pathogen carriers and animal handling. The swine population totaled 74,650 registered animals and $44 \mathrm{TU}(80.0 \%)$ were in the cerrado region. In regard to the number of pigs, $10.9 \%, 9.1 \%, 14 \%, 18.2 \%, 21.8 \%$ and $25 \%$ had $1-10,11-100,101-500,501-1,000$, $1,001-2,000$ and up to 2,000 pigs respectively. Integrated farms totaled $63.6 \%$, while $89.1 \%$ utilized intensive management. The analysis of positive correlations $(\mathrm{P}<0.05)$ were observed in various types of farms, with relation to: veterinary care, all-in all-out systems, carcass incineration, fire sweeping, composting, masonry and wood buildings, consumption of self-produced and commercial food, water supply by dam, river or streams, and fly control. With different correlation levels, numerous deficits were detected in the health management in various segments of the

\footnotetext{
${ }^{2}$ Instituto de Defesa Agropecuária do Estado de Mato Grosso, Cuiabá, MT, Brasil.

${ }^{3}$ Universidade Federal de Mato Grosso, Faculdade de Agronomia, Medicina Veterinária e Zootecnia, Departamento de Ciências Básicas e Produção Animal, Cuiabá, Mato Grosso, Brasil.

*Programa de Pós-Graduação em Ciências Veterinárias, Faculdade de Agronomia, Medicina Veterinária e Zootecnia da Universidade Federal de Mato Grosso.
} 
FUs, so biosecurity issues of farms in Mato Grosso State should be revised, in order to assess their degree of vulnerability.

KEY WORDS: Farms, animal health, swine breeding, Mato Grosso.

\section{INTRODUÇÃO}

SegundoOrganismoaFAO(Food and Agriculture Organization), das Nações Unidas para Alimentação e Agricultura da a proteína animal mais consumida mundialmente é a carne suína, respondendo por $37,4 \%$ da ingestão proteica anual per capita (FAOSTAT, 2011). No Brasil, o consumo de carne suína tem sido determinado em grande parte pelas condições do mercado externo, oscilando entre 11 e $14 \mathrm{~kg} / \mathrm{habi}$ tante/ano (ASSOCIAÇÃo BRASILEIRA..., 2010), podendo variar conforme região em função de hábitos, proibições religiosas ou dogmáticas.

Em Mato Grosso, o rebanho suíno encerrou o ano de 2009 com uma população de 1.427.577 animais, sendo 316.081 de subsistência, 771.894 de granjas comerciais e 339.602 de Granjas de Reprodutores Suídeos Certificada (GRSC). O rebanho comercial totalizou 98.152 matrizes, sendo que 25.602 dessas estão nas GRSC e 72.550 em granjas comerciais (SARTOR, mensagem pessoal). O grande crescimento da suinocultura no estado é impulsionado, pela alta produtividade de grãos, sobretudo milho e soja, principais ingredientes para formulação da ração para suínos (ASSOCIAÇÃo DOS CRIADORES..., 2010).

Nas últimas décadas, os sistemas de produção de suínos tiveram uma grande e rápida evolução e de forma permanente levando a adoção de métodos mais confinados, com o aumento da densidade de animais nas instalações, maior número de instalações por granjas e maior concentração de granjas em limitadas áreas geográficas. Porém, a produção de suínos em múltiplos sítios apresenta mais problemas respiratórios que as granjas de ciclo completo, sendo que a transferência contínua de animais ao mesmo tempo e de diversas origens para uma única unidade de terminação pode contribuir para o aparecimento das pneumonias (BARCELlos et al., 2008b). Com isso, ampliou-se o risco do surgimento de doenças transmissíveis, principalmente quando as granjas apresentam alto grau de vulnerabilidade às doenças (SOBESTIANSKY, 2002).

Dentro deste contexto, o presente trabalho objetivou descrever e analisar as principais características produtivas e sanitárias das unidades de terminação suinícolas comerciais do Estado de Mato Grosso. Com este propósito, pretende-se fornecer dados que poderão aperfeiçoar a obtenção de informações sobre a suinocultura matogrossense, como parte do Programa Nacional do MAPA e subsidiar normativas para o Programa Estadual de Sanidade Suídea (PESS-MT) do INDEA-MT.

\section{MATERIAL E MÉTODOS}

O presente estudo foi realizado em 55 granjas de terminação, distribuídas em 18 municípios do Estado de Mato Grosso: Campo Verde, Cotriguaçu, Guarantã do Norte, Ipiranga do Norte, Jauru, Lucas do Rio Verde, Mirassol D'Oeste, Nova Canaã do Norte, Nova Mutum, Porto Esperidião, Poxoréo, Primavera do Leste, Rondonópolis, Sapezal, Sinop, Sorriso, Santa Rita do Trivelato Tapurah, no período de dezembro de 2005 a janeiro de 2006.

Foram analisadas características que fazem parte do cadastro padrão oficial para granjas comerciais, de onde foram extraídas as variáveis produtivas e sanitárias. Essas características foram analisadas descritivamente para a totalidade de granjas terminadoras no estado, para o número de animais, aspectos produtivos, sistemas de proteção sanitária, controle de possíveis veiculadores de agentes patogênicos e manejo dos animais.

As informações coletadas alimentaram um banco de dados utilizando software Microsoft Excel 2007 ( ${ }^{\circ}$ Microsoft) para a consolidação dos registros e posterior estudo descritivo e analítico. Posteriormente, aplicou-se o teste de correlação Spearman, com o auxílio do software SPSS versão $9.0\left({ }^{\circ}\right.$ SPSS Inc.) a fim de medir o grau de correlação. Para facilitar a compreensão e discussão dos resultados, optou-se por confrontar as variáveis produtivas e sanitárias.

\section{RESULTADOS E DISCUSSÃO}

Das 55 granjas de terminação, $44(80,0 \%)$ concentraram-se no cerrado, mais precisamente na região centro e médio norte, onde se localiza a maior produção de grãos de milho e soja, principais componentes da alimentação dos suínos (INSTITUTO..., 2010).

A população suína cadastrada das unidades terminadoras totalizou 74.650 animais. Entre 2000 a 2005, o rebanho de MT cresceu $61,3 \%$ e o volume exportado em 2002, de $28.875 \mathrm{~kg}$ aumentou para 5.340.054 kg em 2005 (Instituito de Pesquisa..., 2009). Com o aumento constante nos índices de produtividade, a agricultura da região do cerrado mato-grossense vem demonstrando ao longo dos anos melhorias contínuas na produção agrícola, impulsionando o ciclo agroindustrial (INSTITUTO, 2010). Além disso, o papel que a região exerce sobre a responsabilidade de abastecimento das indústrias transformadoras é de grande importância por sua produção. 
As granjas terminadoras estudadas foram estratificadas entre as variáveis analisadas: tipo de produção, comercialização, sistema produtivo, edificação e dados relacionados a sanidade, de acordo com as Tabelas 1 e 2 . Nem todas as granjas apresentaram todos os dados no formulário por isso algumas variáveis possuíram " $n$ " menor que 55 unidades.

Tabela 1 - Descrição das variáveis relativas às granjas terminadoras de suínos no Estado de Mato Grosso de dezembro de 2005 a janeiro de 2006, segundo produção animal, comercialização, sistemas produtivos e de construção.

\begin{tabular}{|c|c|c|}
\hline \multirow{2}{*}{ Variáveis } & \multicolumn{2}{|c|}{ Granjas terminadoras** } \\
\hline & $\mathrm{N}$ & $\%$ \\
\hline \multicolumn{3}{|l|}{ Número de animais } \\
\hline 1 a 10 & 6 & 10,9 \\
\hline 11 a100 & 5 & 9,1 \\
\hline 101 a 500 & 8 & 14,5 \\
\hline 501 a 1000 & 10 & 18,2 \\
\hline 1001 a 2000 & 12 & 21,8 \\
\hline$>2000$ & 14 & 25,4 \\
\hline \multicolumn{3}{|l|}{ Forma de comercialização } \\
\hline Independente & 18 & 32,7 \\
\hline Integrado & 35 & 63,6 \\
\hline \multicolumn{3}{|l|}{ Sistema de exploração } \\
\hline Intensivo & 49 & 89,1 \\
\hline Extensivo & 2 & 3,64 \\
\hline Mista & 2 & 3,64 \\
\hline \multicolumn{3}{|l|}{ Tecnificação* } \\
\hline Sim & 40 & 72,7 \\
\hline Não & 6 & 10,9 \\
\hline \multicolumn{3}{|l|}{ Tipo de edificação } \\
\hline Alvenaria & 39 & 70,9 \\
\hline Mista (alvenaria/madeira) & 10 & 18,2 \\
\hline Madeira & 4 & 7,3 \\
\hline \multicolumn{3}{|l|}{ Tipo de cerca } \\
\hline Tela & 4 & 7,3 \\
\hline Arame & 9 & 16,4 \\
\hline Ausente & 34 & 61,8 \\
\hline \multicolumn{3}{|c|}{$\begin{array}{l}\text { *Uso de tecnologias e com controle deíndices de produção } \\
\text { na granja (Fonte: INDEA, 2008). } \\
\text { **Nem todas as granjas (ou formulários) forneceram todos } \\
\text { os dados solicitados, por isso algumas variáveis possuem } \\
\text { “n” menor que } 55 \text {. }\end{array}$} \\
\hline
\end{tabular}

Os resultados das análises de correlação entre variáveis de caráter sanitário e produtivo encontram-se apresentados nas Tabelas 3 e 4 . As variáveis de caráter sanitário são fatores de riscos importantes para introdução e/ou disseminação de agentes infecto-parasitários e comumente fazem parte da avaliação de vulnerabilidade de granjas, uma vez que certos patógenos de veiculação aerógena e/ou carreadas pela movimentação humana (automóveis, animais de transporte, roupas, calçados) podem comprometer a suinocultura local, predispondo a ocorrência de doenças respiratórias nos suínos (SobestiansKy, 2002). Paralelamente, a densidade populacional e o volume de ar disponível por animal podem influenciar os níveis de aerossóis no ar e a pressão de infecção. Em estudo prévio, onde se avaliaram o efeito "densidade animal" e a ocorrência de doenças respiratórias, as granjas com mais de 500 animais por instalação, espaço aéreo por animal inferior a $3 \mathrm{~m}^{3}$ e menos de $0,7 \mathrm{~m}^{2}$ de piso por leitão apresentaram-se mais susceptíveis a doenças respiratórias (BARCELLOS et al., 2008b). No presente estudo, embora não tenha sido avaliada a densidade populacional das granjas, $25 \%$ das granjas apresentaram número de animais superior a 2.000 suínos em terminação.

No que diz respeito ao controle de possíveis vetores, reservatórios ou fômites, levou-se em consideração a possibilidade de entrada de patógenos na granja, abordando-se controle de roedores, moscas, veículos e visitas. Nesse quesito, observou-se a fragilidade das granjas, pois $49,1 \%$ não controlam roedores, $60,0 \%$ moscas, $81,8 \%$ entrada de veículos automotores e $63,6 \%$ as visitas às granjas, o que possibilita a introdução de patógenos respiratórios graves conforme afirmado por SOBESTIANSKY; BARCELLOS (2007).

Entre as granjas que comercializam produtos por integração, apenas o controle de moscas apresentou correlação positiva. Por outro lado, as outras variáveis de cunho sanitário apresentaram correlação pouco significativa e até negativa em alguns casos, demonstrando falhas nestes manejos, uma vez que os sistemas de integração normalmente exigem maior tecnificação, condições de manejo produtivo e sanitário das granjas. As variáveis sobre edificação de alvenaria e alimentação comercial (ração comercial) apresentaram correlação desejáveis provavelmente justificados pelas exigências do sistema de integração.

Em se tratando de alimento e água, em $43,6 \%$ das granjas, a ração é preparada na própria propriedade e 76,4\% das granjas utilizam poços artesianos como fonte de água. Observou-se que nas propriedades tecnificadas e nas pequenas granjas (até 10 animais) as principais fontes de água são rios e córregos. Embora haja poucos relatos de prejuízos produtivos em decorrência de procedência ou da qualidade da água (SOBESTIANSKY, 2002), a origem da água de consumo deve ser acompanhada por análise físico-química e microbiológica constantes como profilaxia para introdução de doenças transmissíveis (Associação Paulista..., 2011). Como exemplo, pode ser citado o vírus da Síndrome Respiratória e Reprodutiva dos Suínos (SRRS) que pode permanecer viável em água potável, assim como agentes bacterianos ou parasitários, os quais podem inclusive serem disseminados por veiculação mecânica (BARCELLOS et al., 2008a). 
Tabela 2 - Descrição das variáveis relativas às granjas terminadoras de suínos no Estado de Mato Grosso de dezembro de 2005 a janeiro de 2006, segundo variáveis referentes a sanidade animal.

\begin{tabular}{|c|c|c|}
\hline \multirow{2}{*}{ Variáveis } & \multicolumn{2}{|c|}{ Granjas terminadoras* } \\
\hline & $\mathrm{N}$ & $\%$ \\
\hline \multicolumn{3}{|l|}{ Controle de roedores } \\
\hline Controla & 28 & 50,9 \\
\hline Não controla & 27 & 49,1 \\
\hline \multicolumn{3}{|l|}{ Controle de moscas } \\
\hline Controla & 22 & 40,0 \\
\hline Não controla & 33 & 60,0 \\
\hline \multicolumn{3}{|c|}{ Controle de entrada de veículos automotores } \\
\hline Controla & 10 & 18,2 \\
\hline Não controla & 45 & 81,8 \\
\hline \multicolumn{3}{|l|}{ Controle de entrada de visitas } \\
\hline Controla & 12 & 21,8 \\
\hline Não controla & 35 & 63,6 \\
\hline \multicolumn{3}{|c|}{ Procedência da fonte de água fornecida } \\
\hline Poço artesiano & 42 & 76,4 \\
\hline Represa & 1 & 1,8 \\
\hline Rio/córrego & 7 & 12,7 \\
\hline Outros & 1 & 1,8 \\
\hline \multicolumn{3}{|l|}{ Tipo de alimentação fornecida } \\
\hline Ração preparo próprio & 24 & 43,6 \\
\hline Ração comercial & 20 & 36,4 \\
\hline Subprodutos de origem animal & 2 & 3,6 \\
\hline Lavagem & 0 & 0,0 \\
\hline \multicolumn{3}{|l|}{ Tipo de manejo } \\
\hline All-in all-out & 33 & 60,0 \\
\hline Contínuo & 13 & 23,6 \\
\hline \multicolumn{3}{|c|}{ Tipo de desinfecção das instalações } \\
\hline Água e desinfetante & 31 & 56,4 \\
\hline Vassoura de fogo & 24 & 43,6 \\
\hline Calagem & 0 & 0,0 \\
\hline \multicolumn{3}{|c|}{ Realiza vazio sanitário após higienização } \\
\hline Realiza & 30 & 54,5 \\
\hline Não realiza & 25 & 45,4 \\
\hline \multicolumn{3}{|l|}{ Destinação de cadáveres } \\
\hline Incineração & 1 & 1,8 \\
\hline Compostagem & 17 & 30,9 \\
\hline Enterra & 27 & 49,1 \\
\hline Outros & 6 & 10,9 \\
\hline \multicolumn{3}{|l|}{ Utilização de quarentenário } \\
\hline $\operatorname{Sim}$ & 3 & 5,4 \\
\hline Não & 44 & 80,0 \\
\hline \multicolumn{3}{|l|}{ Assistência médica veterinária } \\
\hline Sim & 43 & 78,2 \\
\hline Não & 8 & 14,5 \\
\hline
\end{tabular}

*Nem todas as granjas (ou formulários) forneceram todos os dados solicitados, por isso algumas variáveis possuem " $\mathrm{n}$ " menor que 55.

Com relação ao manejo dos suínos nas instalações, observou-se que 60,0\% das granjas utilizavam o sistema "todos dentro - todos fora" (All-in All-out), sendo essa outra importante barreira sanitária para a entrada de patógenos (SOBESTIANSKY, 2002). Essa variável apresentou correlação positiva com granjas com população de 11 a 100 animais, com granjas tecnificadas e de mercado independente. Por outro lado, foi observada correlação negativa quando avaliada frente às granjas de exploração intensiva e de mercado integrado. Esses últimos resultados são preocupantes, pois normalmente haveria de se esperar esse tipo de manejo nesse sistema de mercado e tipo de exploração. 
Tabela 3 - Correlação entre os aspectos produtivos relativos à população de suínos e tecnificação das granjas de terminação do Estado de Mato Grosso em relação às variáveis relacionadas aos aspectos sanitário.

\begin{tabular}{|c|c|c|c|c|c|c|c|}
\hline \multirow{3}{*}{ Variável } & \multicolumn{7}{|c|}{ Aspectos produtivos } \\
\hline & \multicolumn{6}{|c|}{ Número de animais } & \multirow{2}{*}{$\begin{array}{c}\text { Tecnificação } \\
\text { Sim }\end{array}$} \\
\hline & 1 a 10 & 11 a 100 & 101 a 500 & 501 a 1.000 & 1.001 a 2.000 & $>2.000$ & \\
\hline \multicolumn{8}{|l|}{ Aspectos sanitários } \\
\hline Controle de roedores & $-0,048$ & 0,069 & 0,214 & $-0,180$ & $-0,078$ & 0,053 & 0,129 \\
\hline Controle de moscas & $-0,134$ & $-0,129$ & 0,126 & 0,000 & 0,252 & $-0,157$ & $-0,105$ \\
\hline Controle de veículos & 0,039 & 0,149 & 0,194 & $-0,144$ & $-0,093$ & $-0,071$ & 0,191 \\
\hline Controle de visitas & 0,070 & 0,167 & 0,093 & 0,021 & $-0,147$ & $-0,121$ & 0,204 \\
\hline Quarentenário & 0,090 & $-0,192$ & 0,118 & $-0,315^{*}$ & 0,136 & 0,136 & 0,096 \\
\hline All-in All-out & 0,187 & $0,556^{*}$ & $-0,243$ & $-0,066$ & $-0,214$ & $-0,097$ & $0,404^{*}$ \\
\hline Incineração & $-0,052$ & $0,430^{*}$ & $-0,056$ & $-0,064$ & $-0,072$ & $-0,076$ & - \\
\hline Compostagem & $-0,137$ & $-0,212$ & $-0,276^{*}$ & $-0,009$ & $0,313^{*}$ & 0,184 & $-0,269$ \\
\hline Enterra & 0,171 & 0,069 & 0,214 & $-0,180$ & $-0,078$ & $-0,118$ & 0,275 \\
\hline Água e desinfetante & 0,006 & $-0,232$ & 0,259 & 0,130 & $-0,157$ & $-0,028$ & $-0,199$ \\
\hline Vassoura de fogo & 0,116 & $0,278^{*}$ & $-0,157$ & $-0,251$ & 0,021 & 0,058 & 0,146 \\
\hline Calagem & - & - & - & - & - & - & - \\
\hline Assistência Veterinária & $0,298^{*}$ & $0,476^{*}$ & $-0,015$ & $-0,200$ & $-0,226$ & $-0,129$ & $0,883^{*}$ \\
\hline \multicolumn{8}{|l|}{ Edificação } \\
\hline Alvenaria & $-0,019$ & $-0,392^{*}$ & $-0,106$ & $0,271^{*}$ & 0,096 & 0,043 & $-0,578^{*}$ \\
\hline Mista & $-0,046$ & 0,174 & 0,066 & $-0,218$ & $-0,009$ & 0,061 & $0,042^{*}$ \\
\hline Madeira & 0,100 & $0,397^{*}$ & 0,079 & $-0,129$ & $-0,146$ & $-0,163$ & $0,797^{*}$ \\
\hline \multicolumn{8}{|l|}{ Tipo de cerca } \\
\hline Tela & 0,142 & $-0,105$ & $-0,138$ & 0,239 & $-0,159$ & 0,028 & $-0,120$ \\
\hline Arame & $-0,168$ & 0,183 & $-0,077$ & 0,038 & 0,143 & $-0,121$ & $-0,193$ \\
\hline \multicolumn{8}{|l|}{ Alimentação } \\
\hline Ração própria & 0,195 & 0,195 & $-0,135$ & $-0,076$ & $-0,186$ & 0,083 & $0,342^{*}$ \\
\hline Ração comercial & $-0,165$ & $-0,165$ & 0,060 & 0,120 & 0,231 & $-0,143$ & $-0,295$ \\
\hline Subproduto animal & $-0,074$ & $-0,074$ & 0,183 & $-0,105$ & $-0,105$ & 0,146 & $-0,099$ \\
\hline Lavagem & - & - & - & - & - & - & - \\
\hline \multicolumn{8}{|l|}{ Procedência da água } \\
\hline Poço artesiano & 0,009 & $-0,193$ & $-0,225$ & $-0,056$ & 0,136 & 0,243 & $-0,325^{*}$ \\
\hline Represa & $0,387^{*}$ & $-0,047$ & $-0,061$ & $-0,065$ & $-0,078$ & $-0,074$ & $0,383^{*}$ \\
\hline Rio/Córrego & $-0,146$ & 0,060 & $0,298^{*}$ & 0,114 & $-0,087$ & $-0,209$ & 0,032 \\
\hline
\end{tabular}

Relacionando os sistemas de limpeza e desinfecção das instalações, observou-se que $56,4 \%$ e 43,6\% utilizavam água e desinfetante e vassoura de fogo respectivamente, e $54,5 \%$ realizavam vazio sanitário após a desinfecção, sendo esta eficaz barreira sanitária na criação (SOBESTIANSKY; BARCELlOS, 2007). Nesse quesito, verificou-se apenas a correlação positiva com utilização de vassoura de fogo em granjas com população entre 11 a 100 animais. Segundo AMARAL et al. (2006), o emprego da vassoura de fogo deve ser utilizado numa segunda etapa de desinfecção para que possa atuar com maior eficácia frente a esporos e oocistos de parasitas, pois na primeira etapa preconiza-se aspersão de água e desinfetante. Adicionalmente, de acordo com BARCELlos et al. (2008b), o emprego da água na limpeza e desinfecções das instalações reduziu a ocorrência de pleurite em leitões em crescimentos, bem como a diminuição de enteropatógenos no ambiente.

No presente estudo foi demonstrado que a assistência médica veterinária ocorre em $78,2 \%$ das granjas terminadoras de suínos, sendo essa uma importante variável para o controle sanitário das granjas, conforme descreveu SOBESTIANSKY (2002). A assistência veterinária também apresentou correlação positiva nas granjas com até 10 e de 11 a 100 suínos, tecnificadas, de exploração extensiva, mista e independente. Entretanto, foi negativa quando avaliadas nas granjas de exploração intensiva e nas integradas. Estes resultados são preocupantes, pois, em granjas de sistema intensivo integrado, os animais são criados confinados e normalmente assistidos por empresa integradora que fornece assistência médica veterinária e tecnificação. 
Tabela 4 - Correlação entre os aspectos produtivos relativos ao sistema de exploração e forma de comercialização das granas de terminação do Estado de Mato Grosso em relação às variáveis relacionadas aos aspectos sanitário.

\begin{tabular}{|c|c|c|c|c|c|}
\hline \multirow{3}{*}{ Variável } & \multicolumn{5}{|c|}{ Aspectos produtivos } \\
\hline & \multicolumn{3}{|c|}{ Sistema de exploração } & \multicolumn{2}{|c|}{ Forma de comercialização } \\
\hline & Intensivo & Extensivo & Mista & Independente & Integrado \\
\hline \multicolumn{6}{|l|}{ Aspectos sanitários } \\
\hline Controle de roedores & $-0,016$ & 0,011 & 0,011 & $-0,119$ & 0,119 \\
\hline Controle de moscas & 0,194 & $-0,235$ & $-0,034$ & $-0,366^{*}$ & $0,366^{*}$ \\
\hline Controle de veículos & $-0,138$ & 0,095 & 0,095 & 0,142 & $-0,142$ \\
\hline Controle de visitas & $-0,155$ & 0,107 & 0,107 & 0,007 & $-0,007$ \\
\hline Quarentenário & $-0,080$ & 0,055 & 0,055 & 0,027 & $-0,027$ \\
\hline All-in All-out & $-0,492^{*}$ & $0,340^{*}$ & $0,340^{*}$ & $0,353^{*}$ & $-0,353^{*}$ \\
\hline Incineração & 0,040 & $-0,027$ & $-0,027$ & 0,193 & $-0,193$ \\
\hline Compostagem & 0,188 & $-0,130$ & $-0,130$ & $-0,211$ & 0,211 \\
\hline Enterra & $-0,280^{*}$ & 0,194 & 0,194 & $0,305^{*}$ & $-0,305^{*}$ \\
\hline Água e desinfetante & 0,194 & $-0,235$ & $-0,034$ & 0,038 & $-0,038$ \\
\hline Vassoura de fogo & $-0,260$ & 0,180 & 0,180 & 0,252 & $-0,252$ \\
\hline Calagem & - & - & - & - & - \\
\hline Assistência Veterinária & $-0,580^{*}$ & $0,468^{*}$ & $0,328^{*}$ & $0,638^{*}$ & $-0,638^{*}$ \\
\hline \multicolumn{6}{|l|}{ Edificação } \\
\hline Alvenaria & $0,477^{*}$ & $-0,331^{*}$ & $-0,331^{*}$ & $-0,655^{*}$ & $0,655^{*}$ \\
\hline Mista & $-0,410^{*}$ & 0,158 & $0,411^{*}$ & $0,469^{*}$ & $-0,469 *$ \\
\hline Madeira & $-0,189$ & $0,318^{*}$ & $-0,057$ & $0,398^{*}$ & $-0,398^{*}$ \\
\hline \multicolumn{6}{|l|}{ Tipo de cerca } \\
\hline Tela & 0,093 & -0.064 & $-0,064$ & $-0,083$ & 0,083 \\
\hline Arame & $-0,045$ & 0,165 & $-0,103$ & 0,062 & $-0,062$ \\
\hline \multicolumn{6}{|l|}{ Alimentação } \\
\hline Ração própria & $-0,141$ & $-0,009$ & 0,204 & $0,500^{*}$ & $-0,500^{*}$ \\
\hline Ração comercial & 0,115 & 0,028 & $-0,187$ & $-0,613^{*}$ & $0,613^{*}$ \\
\hline Subproduto animal & 0,066 & $-0,045$ & $-0,045$ & 0,266 & $-0,266$ \\
\hline Lavagem & - & - & - & - & - \\
\hline \multicolumn{6}{|l|}{ Procedência da água } \\
\hline Poço artesiano & 0,246 & $-0,170$ & $-0,170$ & $-0,191$ & 0,191 \\
\hline Represa & 0,042 & $-0,029$ & $-0,029$ & 0,190 & $-0,190$ \\
\hline Rio/Córrego & $-0,093$ & $-0,082$ & 0,212 & 0,058 & $-0,058$ \\
\hline
\end{tabular}
${ }^{*} \mathrm{P}<0,05$.

Quanto ao destino de cadáveres, em 49,1\% das granjas estes são enterrados, havendo correlação significativa com granjas que operam em mercado independente. Este destino de carcaças é o método mais comumente empregado e este método é realizado em valas, nem sempre livres de infiltrações, o que pode dificultar o seu uso em épocas de chuvas além de estarem a mercê de animais escavadores, que as descobrem expondo-as ao ambiente. Além do que, geralmente, as valas não possuem fundo revestido, o que aumenta a possibilidade de contaminação das águas subterrâneas por infiltração de líquidos orgânicos (PAIVA; BLEY JUNIOR, 2001). Observou-se a correlação positiva de granjas que incineram cadáveres com propriedades de população entre 11 a 100 animais. Segundo Paiva; Bley Junior (2001), há necessidade de se utilizar combustível para obter altas temperaturas e injeção de ar para aumentar a eficiência de queima, uma vez que a umidade das carcaças é de aproximadamente 65 a $70 \%$, o que eleva os custos desta operação. A compostagem decarcaças é realizada por $30,9 \%$ das granjas, correlacionadas com propriedades de população entre 1.001 a 2.000 animais. A compostagem é um método eficaz e seguro para o destino de cadáveres, por exemplo, em se tratando das GRSC, o processo de compostagem assume a menor pontuação de vulnerabilidade, ou seja, as granjas quenão utilizam esse manejo são mais vulneráveis a ocorrência de doenças (BRASIL, 2002).

Nos dados relacionados ao tipo de exploração observou-se que $89,1 \%$ das granjas são de exploração intensiva, o que é esperado num mercado onde as granjas integradas e tecnificadas são a maioria. Por outro lado, apenas 3,64\% das granjas operam na forma extensiva ou mista. Nestes sistemas os animais são mantidos permanentemente soltos, a campo, às vezes totalmente abandonados em determinada área de terra, caracterizados por criações primitivas, sem utilização de tecnologias adequadas e, portanto, apresentando baixos índices de produtividade 
(SobestiAnsky et al., 1998). As granjas de exploração extensiva e mista apresentaram correlação positiva com manejo "todos dentro todos fora", assistência médica veterinária e às edificações mistas e de madeira, o que denota tentativa de obter um melhor controle sanitário a despeito da falta de tecnificação e adequadas instalações.

Em 61,8\% das granjas avaliadas não foi observado o uso de cercas de arame ou telas. As cercas conferem maior proteção às granjas, devendo ser colocadas uma distância de 20 a 30 m das instalações para dificultarem a entrada de pessoas, animais silvestres e domésticos, garantindo sua biossegurança (Sobestiansky et al., 1998). Para que se tenha eficácia nessa importante barreira, o ideal é que a cerca a ser utilizada seja de tela com adequado diâmetro.

A atividade suinícola brasileira teve um grande desenvolvimento nas últimas décadas, devido a investimentos em tecnologia, manejo do rebanho, nutrição e melhoramento genético. Entretanto, nenhum desses fatores isoladamente é eficaz se a sanidade do plantel não estiver em condições adequadas para seu desenvolvimento (Pereira, 2009). Segundo RACHED (2009), mesmo o Brasil sendo o quarto maior produtor e exportador de carne suína do mundo e com um dos maiores avanços no manejo sanitário e tecnológico, muitas criações não acompanharam essa evolução, da mesma forma que observado nos resultados do presente trabalho. Ressalta-se neste estudo que as questões relativas à biosseguridade dos plantéis de terminação do Estado de Mato Grosso devem ser melhoradas, para que futuramente possa ser avaliado o grau de vulnerabilidade das granjas comerciais, uma vez que foram detectados inúmeros déficits relativos ao manejo sanitário em diversos segmentos das unidades terminadoras.

\section{REFERÊNCIAS}

AMARAL, A.L.; SILVEIRA, P.R.S.; LIMA, G.J.M.M.; KLEIN, C.S.; PAIVA, D.P.; MARTINS, F.; KICH, J.D.; ZANELLA, J.R.C.; FÁVERO, J.; LUDKE, J.V.; BORDIN, L.C.; MIELE, M.; HIGARASHI, M.M.; MORÉS, N.; COSTA, O.A.D.; OLIVEIRA, P.A.V.; BERTOL, T.M.; SILVA, V.S. Boas práticas de produção de suínos. Concórdia: EMBRAPA-Suínos e Aves, 2006. p.7-60. (Circular técnica 50).

ASSOCIAÇÃO BRASILEIRA DA INDÚSTRIA PRODUTORA E EXPORTADORA DE CARNE SUÍNA. ABIPECS. 2010. Disponível em: <http:/ / www.abipecs.org. br/relatorios/rela2008_P.pdf>. Acesso em: 28 abr. 2010.

ASSOCIAÇÃO DOS CRIADORES DE SUÍNOS DE MATO GROSSO. ACRISMAT. 2010. Online. Disponível em: <http://www.acrismat.com.br/novo_site/site/estatistica_nacional.php>. Acesso em: 28 maio 2010.

ASSOCIAÇÃO PAULISTA DE CRIADORES DE SUÍNOS. APCS. 2011. Disponível em: <http:/ / www. suinopaulista.com.br/7,1,26,24040.asp\#>. Acesso em: 1 jan. 2011.

BARCELLOS D.E.S.N.; MORES, T.J.; SANTI, M.; GHELLER N. B. Avanços em programas de biosseguridade para a suinocultura. Acta Scientiae Veterinariae, v.36, p.33-46, 2008a. Suplemento 1.

BARCELLOS, D.E.S.N.; BOROWSKI, S.M.; GHELLER, N.B.; SANTI, M.; MORES, T.J. Relação entre ambiente, manejo e doenças respiratórias em suínos. Acta Scientiae Veterinariae, v.36, p.87-93, 2008b. Suplemento 1.

BRASIL. Ministério da Agricultura, Pecuária e Abastecimento. Secretaria de Defesa Agropecuária. Instrução Normativa/SDA n ${ }^{\circ} 19$, de 15 de fevereiro de 2002. Normas para a Certificação de Granjas de Reprodutores Suídeos (GRSC). Diário Oficial [da] República Federativa do Brasil. Brasília, [sp], 01 de março de 2002, Seção 1. $n^{\circ} 41$.

FAOSTAT. FAO Statistics: Food Balance Sheets. 2011. Disponível em: <http:/ / faostat.fao.org/site/368/DesktopDefault. aspx?PageID=368\#ancor $>$. Acesso em: 29 ago. 2011.

INSTITUTO MATOGROSSENSE DE ECONOMIA AGROPECUÁRIA. IMEA. Potencial produtivo da região Centro Norte. Disponível em: <http:/ / www.imea.com. br/upload/pdf/arquivos/Potencial_Produtivo_da_Regiao_Centro_Norte.pdf>. Acesso em: 28 dez. 2010.

INSTITUTO DE DEFESA AGROPECUÁRIA DO ESTADO DE MATO GROSSO-INDEA/MT. Cadastro de propriedades com suínos. Cuiabá: INDEA, 2009.

PAIVA, D.P.; BLEY JUNIOR, C. Emprego da compostagem para destinação final de suínos mortos e restos de parição. Concórdia: EMBRAPA, 2001. p.1-10. (Circular técnica 26).

PEREIRA, J.A. Soroprevalência da infecção por Leptospira spp. em matrizes suínas oriundas do médio norte do estado de Mato Grosso, Brasil. 2009. 12-14p. Dissertação (Mestrado em Ciências Veterinárias) - Faculdade de Agronomia, Medicina Veterinária e Zootecnia, Universidade Federal de Mato Grosso, Cuiabá, 2009.

RACHED, R.Z. Caracterização de pequenas criações de suínos no Estado de São Paulo. 2009. 149p. Dissertação (Mestrado em Sanidade Animal, Segurança Alimentar e o Ambiente) - Instituto Biológico, São Paulo, 2009.

SOBESTIANSKY, J. Sistema intensivo de produção de suínos: programa de biossegurança. Art. 3 Impressos Especiais ISO-9002. Goiânia, GO, 2002. 108p. 
SOBESTIANSKY, J.; BARCELLOS, D. Doenças de suínos. Goiânia: Cânone Editorial, 2007. 770p.

SOBESTIANSKY, J.; WENTZ, I.; SILVEIRA, P.R.S.

da; SESTI, L.A.C. Sistema de Produção de Suínos. In: NICOLAIEWSKY, S.; WENTZ; COSTA, O.A.D.; SOBESTIANSKY, J. Suinocultura Intensiva: produção, manejo e saúde do rebanho. Brasília: Embrapa-SPI, EmbrapaCNPSa, 1998. p.13-43.

Recebido em $21 / 2 / 11$

Aceito em 14/5/12 